\title{
A Quantitative Scenario Analysis Method for Ecological Safety Development Trends in Rare Earth Mining Areas
}

\author{
Wang Rui ${ }^{1,2}$, Liu Li-gang ${ }^{1,2, *}$, Zhen Ming-gui ${ }^{3}$, Liu Yi-qing ${ }^{1,2}$, Li Di $^{4,5}$ and Fu hui-juan ${ }^{2}$ \\ ${ }^{1}$ Mining developments research center, Jiangxi University of Science and Technology, Ganzhou 341000, China \\ ${ }^{2}$ School of Economics \& Management, Jiangxi University of Science and Technology, Ganzhou 341000, China \\ ${ }^{3}$ Faculty of Foreign Studies, Jiangxi University of Science and Technology, Ganzhou 341000, China \\ ${ }^{4}$ School of Management, Wuhan Univeristy of Technology, Wuhan 430070, China \\ ${ }^{5}$ DeGroote School of Business, McMaster University, Hamilton, ON L8S-4M4, Canada
}

Received 21 May 2019; Accepted 14 September 2019

\begin{abstract}
Rare earth mining can cause ecological problems as a result of soil erosion and water pollution in local areas. Thus assessing the development trends of ecological safety is crucial in formulating the environmental protection policies in rare earth area. Rare earth mining is a long and complicated process in which the state values of evaluation indicators for ecological safety are dynamic and continual interplay. Hence, conventionally measured indicators are inadequate in this context. An evaluation method based on the theory of quantitative scenario analysis was proposed in this study to analyze ecological safety development trends in rare earth mining areas. First, according to the PSR model framework, six indicators including "mining technology", "mining intensity", "water environment", "soil environment", "waste water, waste gas and waste residue management technologies" and "environmental protection policy", were selected to reveal the ecological safety in mining areas. Second, the crossover probability algorithm, Markov chain and nonlinear programming were utilized to construct a quantitative scenario analysis model for ecological safety development trends. Lastly, the model was verified using the data on Lingbei rare earth mining area located in Ganzhou City, China. Results showed that the quantitative scenario analysis model could be used to calculate the changes in various indicators, their cross impacts in the development process and the occurrence probability of scenario combinations for ecological safety development that were composed of the state changes of each indicator. These findings indicate that the proposed model can effectively and accurately forecast the ecological safety development trends in rare earth mining areas. The conclusions can provide a theoretical basis for environmental protection work in rare earth mining areas.
\end{abstract}

Keywords: Rare earth mining areas, Quantitative scenario, PSR framework, Ecological safety

\section{Introduction}

Rare earth is one of the most important resources of a national economy, and it is particularly crucial to the hightech manufacturing industries. The demand for rare earth in China is increasing with the economic restructuring and industrial upgrading in the country. The government has difficulties monitoring rare earth mining, because rare earth resources are distributed in remote mountainous areas characterized by tall mountains, lush forests, and disperse mineral occurrences. As a result, many ecological problems, such as vegetation destruction and erosion, have emerged due to the disorderly mining of rare earth ores, and these problems have caused serious environmental damage [1-2]. Eco-environmental problems in mining areas have become increasingly serious because of the mining boom, which has deleterious effects on local ecological civilization construction. Thus, the evaluation of ecological safety development in rare earth mining areas has become an important research topic in ecological safety. Such an evaluation can provide a theoretical basis for the formulation

*E-mail address: 250187106@qq.com

ISSN: 1791-2377 С 2019 School of Science, IHU. All rights reserved.

doi:10.25103/iestr.125.25 and implementation of policies.

Rare earth mining is a long-term process, and ecological safety in mining areas is influenced by various indicators from different dimensions, such as "mining technology", "water environment in the mining area" and "waste water, waste gas and waste residue management technologies "(three-waste management technologies ) [3]. The states of these indicators are affected not only by external factors such as scientific and technological development, but also affected by the indicators themselves. For example, mining technology becomes increasingly advanced with technological development, and a change in mining technology can affect the state values of other indicators of ecological safety in mining areas, such as water environment. Therefore, these state values present dynamic changes in the evaluation process of ecological safety in rare earth mining areas. Conventional evaluation methods, such as analytic hierarchy process (AHP) and fuzzy synthetic evaluation methods normally assess ecological safety in mining areas on the basis of the state values of evaluation indicators. However, they can not reflect the development trends of evaluation indicators. Thus, providing a novel approach that can scientifically realize a quantitative analysis of the change scenarios of evaluation indicators of 
ecological safety in rare earth mining areas is essential in evaluating the development trends of ecological safety.

\section{State of the art}

With the propulsion of ecological civilization strategies in China, ecological safety problems in mining areas have attracted much attention from scholars in recent years. Research in this domain has focused on the evaluation indicator system and evaluation methods of ecological safety. In the field of evaluation indicators design, the pressurestate-response (PSR) theoretical framework was primarily used to construct the evaluation index system of regional ecological safety. For instance, Gosselin (2012) constructed an evaluation indicator system for ecological safety in forest areas from the perspective of ecological diversity on the basis of the PSR framework, and then the ecological safety in forest areas in Europe was evaluated by the indicator system [4]. Sun (2018) and Cen (2015) et al. built an evaluation indicator system for urban ecological safety from dimensions of urban population and landscape on the basis of the PSR framework, and used the system to evaluate the ecological safety of city agglomeration in Pearl River Delta and Hangzhou City [5-6]. Rapport (2013), Seydehmet (2018), and Shi (2018) designed an evaluation indicator system for ecological safety in ecological function areas from the perspectives of economic environment and social environment, and they evaluated the ecological safety in desert oasis ecological function areas in Xinjiang Province, China, and in urban mudflat ecological function areas in Shanghai City, China, by using their designed system [7-9]. However, since mining area is quite different from nonmining area, such as cities and ecological function areas that are scarcely influenced by three-waste management technology and mining technology, the evaluation indicators for ecological safety in such areas as cities are inapplicable to mining areas.

Given this background, scholars have proposed evaluation indicator systems for ecological safety against the features of mining areas on the basis of the PSR framework. Neri (2016) proposed an evaluation indicator system for ecological safety in iron mining areas from perspectives of natural vegetation and air quality based on PSR framework, and he evaluated the ecological safety of an iron mining area in the southeast of Brazil [10]. Malenović (2016), He (2017), and $\mathrm{Ke}(2018)$ proposed an evaluation indicator system for ecological safety in coal mining areas from dimensions of resource mining intensity and economic benefit by adopting the PSR framework, and they evaluated ecological safety in Kostolac coal mine in Serbia and Zhengzhou coal mine in China [11-13]. Compared with the technology of rare earth mining, the mining technology of mineral products, such as coal and iron, is quite mature with highly standardized mining technology that has less impact on ecological safety. The mining technology of rare earth is complicated, and great differences exist among different mining technologies, such as dump and in-situ leaching methods in terms of type and dosage of required ionic exchange liquids. These differences in mining technologies exert a critical effect on ecological safety in rare earth mining areas. Given the maturity and influence of mining technology difference, the evaluation indicators proposed by $\mathrm{He}$ et al, cannot be directly applied to the evaluation of ecological safety in rare earth mining areas. Therefore, it is necessary to construct a set of evaluation indicators about ecological safety in rare earth mining areas based on PSR framework.

Currently, the dominant evaluation methods of ecological safety include the AHP model, fuzzy synthetic evaluation and artificial neural network. Stecyk (2019) utilized the AHP-TOPSIS method to evaluate the ecological safety situation in Pomeranian, Poland, by using data from 2010-2017 [14]. Alilou (2019) and Xue (2016) et al. evaluated ecological safety in river drainage basins and mining areas by using the fuzzy analytic network process, fuzzy AHP, and other methods [15-16]. In accordance with the ecological footprint information of 22 provinces in China, Wang et al. (2018) used the linear auto-regression neural network model to evaluate the ecological safety state in China [17]. Although these evaluation methods have been widely applied to the field of ecological safety evaluation and achieved satisfactory results, they still have drawbacks. When these methods are used, processing the state values of evaluation indicators with dynamic changes is difficult. That is to say, these methods evaluate the ecological safety state in mining areas by taking the indicators' values in a certain period as the benchmark without considering the dynamic changes in the state values of these indicators in the development process of mineral resources. Moreover, the AHP method and fuzzy synthetic evaluation can hardly process the situations wherein evaluation indicators are associated with one anther to some extent. Among the indicators that affect ecological safety in rare earth mining areas, mining technology, mining intensity and others have correlations, and the dynamic changes in the state values of these indicators usually generate a cross impact on the changes of state values of other indicators. Therefore, it is difficult to evaluate the development trend of ecological safety in the rare earth mining area with the conventional evaluation method such as AHP.

Quantitative scenario analysis, a quantitative evaluation of the development scenarios of things, has been applied to fields, such as evaluating the development trends of organizational strategies. Quiceno (2019) and Höltl (2019) et al. combined the quantitative scenario analysis method with qualitative analysis methods, such as DELPHI to perform a dynamic analysis of the development trends of industries, such as the Columbian electric industry and the European new energy vehicle industry [18-19]. However, few studies have analyzed the ecological safety development trends in mining areas by using the quantitative scenario analysis method. The environment surrounding ecological safety development in rare earth mining areas is an ever-changing scenario consisting of various influence factors with a strong dynamic nature. Therefore, this study aimed to use quantitative scenario analysis method to conduct a quantitative analysis of ecological safety development trends in rare earth mining areas.

The remainder of this study was organized as follows. In Section 3, evaluation indicators that reflect ecological safety development in rare earth mining areas were proposed in accordance with the PSR framework, and a detailed introduction of the quantitative scenario analysis model for ecological safety development trends in rare earth mining areas was provided by adopting cross-scenario probability, Markov chain and nonlinear programming. In Section 4, the model was verified based on ecological data in Lingbei rare earth mining area in Ganzhou, China. At last, The conclusions, contributions, and implications and several directions for future research were outlined in the final section. 


\section{Methodology}

3.1 Evaluation indicators for ecological safety in rare earth mining areas on the basis of the PSR framework

The PSR framework model is a conceptual model proposed by OECD and UNEP to evaluate ecosystem safety and sustainability [20]. The framework analyzes the internal causal relationship in the ecosystem and constructs a causal chain between human activity and ecological environment on the basis of the causal relationship. PSR has been used to diagnose the sustainability and safety of ecosystems. It has been extensively applied to the safety evaluation of regional ecosystems and has obtained satisfactory achievements. In accordance with the PSR framework, indicators that reflect ecological safety in rare earth mining areas have been determined from three dimensions: pressure, state and response.

In the pressure dimension, several mining technologies, such as pool and dump leaching methods, destruct vegetations in the mining area in a large scale and form a severe impact on stability of its ecosystem [21]. Therefore, mining technology is an indicator that reflects ecological safety in rare earth mining areas, and it is represented by $C_{1}$. In addition, mining intensity also has a great effect on the ecological environment. High mining intensity equates to high ecological pressure. Hence, mining intensity is also an indicator that reflects ecological safety in the rare earth mining areas, and it is represented by $C_{2}$.

State-level indicators are used to characterize ecological safety in the rare earth mining areas. Given that rare earth generates a large quantity of sediments during mining and that most rare earth mining areas are located in Southern China with many rainy days that cause soil erosion in mining areas [22]. The soil environment in mining areas is an important indicator that reflects ecological safety, and it is represented by $C_{3}$. Regardless of the mining technology used in the mining process, mineral leaching technology is required to extract rare earth ions. Mineral leaching liquid pollutes surface water and underground water in the mining areas. Therefore, the water environment in the mining areas also can reflect the ecological safety state, and it is represented by $C_{4}$.

Response refers to the act people implement positive remedial measures after perceiving the pressure of ecological safety in the rare earth mining areas [23]. In this aspect, management technologies, such as discharge management of waste water and gas, waste residue management, and environmental protection policy measures (e.g., special fund devoted to environmental protection) are mainly used to improve the ecological environmental status in mining areas. Therefore, three-waste management technology and environmental protection policy are indicators reflecting ecological safety development levels in rare earth mining areas, and they are represented by $C_{5}$ and $C_{6}$, respectively.

These evaluation indicators reflecting ecological safety development in rare earth mining areas from pressure, state and response dimensions are shown in Table 1.

Table 1. List of evaluation indicators reflecting ecological safety development in rare earth mining areas

\begin{tabular}{c|c|c|c} 
Target & Criteria Layer & Indicators & Influence \\
\hline Ecological & Pressure & Mining technology & Positive
\end{tabular}

\begin{tabular}{c|c|c|c}
\hline $\begin{array}{c}\text { safety in } \\
\text { rare earth } \\
\text { mining } \\
\text { areas }\end{array}$ & & $\left(C_{1}\right)$ & \\
& State & $\begin{array}{c}\text { Mining intensity }\left(C_{2}\right) \\
\text { Soil environment } \\
\left(C_{3}\right)\end{array}$ & Negative \\
& & $\begin{array}{c}\text { Water environment } \\
\left(C_{4}\right)\end{array}$ & Positive \\
& & $\begin{array}{c}\text { Three-waste } \\
\text { management } \\
\text { technology }\left(C_{5}\right)\end{array}$ & Positive \\
& Response & environmental \\
& & Protection policy $\left(C_{6}\right)$ & Positive \\
\hline
\end{tabular}

3.2 Quantitative scenario analysis method for ecological safety development trends in rare earth mining areas

The environment faced by ecological safety development in rare earth mining areas is an ever-changing scenario consisting of various influence factors with strong dynamic nature. Therefore, Markov chain and the nonlinear programming method are combined to construct a quantitative scenario analysis model, which is utilized to analyze development scenarios of ecological safety in rare earth mining areas. As a forecasting analysis method, quantitative scenario analysis method has been utilized in the military field at the earliest. In comparison with traditional forecasting methods, the quantitative scenario analysis method accepts the diversity of future development with many possible development trends. In the forecasting analysis process, the dynamic role of humans is fully considered, and by combining qualitative methods, forecasters can easily utilize abstract thinking to handle technological, social, economic, political affairs and other uncertainties and emergencies. The implementation steps are as follows.

Step-1: The status value of evaluation indicators for ecological safety in the rare earth mining areas is determined. The rules are shown in Table 2.

Table 2. Status value of indicators

\begin{tabular}{c|c|c}
\hline Indicators & State & Value \\
\hline Mining technology & Non-significant improvement & 0 \\
$\left(C_{1}\right)$ & Significant improvement & 1 \\
Mining intensity $\left(C_{2}\right)$ & Decrease & 0 \\
Increase & 1 \\
Soil environment $\left(C_{3}\right)$ & Non-significant improvement & 0 \\
Water environment & Significant improvement & 1 \\
$\left(C_{4}\right)$ & Non-significant improvement & 0 \\
Three-waste & Significant improvement & 1 \\
management technology & Non-significant improvement & 0 \\
$\left(C_{5}\right)$ & Significant improvement & 1 \\
environmental protection & Non- significant effect & 0 \\
policy $\left(C_{6}\right)$ & Significant effect & 1 \\
\hline
\end{tabular}

Step-2: Permutation and combination are conducted in accordance with the development trends of different influence factors, and an initial scenario scheme is formed. The scheme is then simplified logically. The process is as follows.

The initial probability matrix for all indicators, which is represented by $P$, is set in accordance with related expert experience to develop toward the favorable direction.

$$
P=\left(p_{1}, p_{2}, \ldots, p_{i}, \ldots\right)
$$


In above formula, $p_{i}$ represents the initial probability for indicator $C_{i}$ towards the favorable direction. In accordance with experts' experience, the influence matrix $K$ of the indicators on other indicators in the change process is determined.

$$
K=\left[\begin{array}{c}
K_{1} \\
K_{2} \\
\ldots \\
K_{i} \\
\ldots
\end{array}\right]=\left[\begin{array}{ccccc}
k_{11} & k_{12} & \ldots & \ldots & \ldots \\
k_{21} & \ldots & \ldots & \ldots & \ldots \\
\ldots & \ldots & \ldots & \ldots & \ldots \\
k_{i 1} & \ldots & k_{i j} & \ldots & \ldots \\
\ldots & \ldots & \ldots & \ldots & \ldots
\end{array}\right]_{n \times n}
$$

Where, $k_{i j}$ is the influence degree of the state value change of indicator $C_{i}$ on the state value of indicator $C_{j}$. Following Pearson correlation coefficient rules [24], the value rule and meaning of $k_{i j}$ are listed in Table 3.

Table. 3. Value of $k_{i j}$

\begin{tabular}{c|c}
\hline Range of value & Meaning \\
\hline $0.66<k_{i j} \leq 1$ & $C_{i}$ has a strong positive effect on $C_{j}$ \\
$0.33<k_{i j} \leq 0.66$ & $C_{i}$ has a positive effect on $C_{j}$ \\
$0<k_{i j} \leq 0.33$ & $C_{i}$ has a weak positive effect on $C_{j}$ \\
$k_{i j}=0$ & $C_{i}$ has no effect on $C_{j}$ \\
$-0.33 \leq k_{i j}<0$ & $C_{i}$ has a weak negative effect on $C_{j}$ \\
$-0.66 \leq k_{i j}<-0.33$ & $C_{i}$ has a negative effect on $C_{j}$ \\
$-1 \leq k_{i j}<-0.66$ & $C_{i}$ has a strong negative effect on $C_{j}$
\end{tabular}

According to the initial probability matrix $P(i)$ and mutual influence matrix $K$ among indicators, the scenario combinations constituted by the indicators as shown in Table 1 are analyzed. Scenarios combinations wherein the indicators are in conflict are eliminated. Then, the scenario set can be obtained.

$$
E=\left(E_{1}, E_{2}, \ldots, E_{k}, \ldots, E_{n}\right)
$$

In formula (3), $E_{k}$ denotes the $k$ (th) scenario scheme formed by the combination in Table 2, and it can be expressed by the following formula.

$$
E_{k}=\left(e_{c 1}, e_{c 2}, e_{c 3}, e_{c 4}, e_{c 5}, e_{c 6}\right)^{T}
$$

Where, $e_{c i}$ is the state value of indicator $C_{i}$ in scenario. Its values are shown in Table 2.

Step-3: A quantitative scenario analysis model is built based on cross-impact probability, Markov chain and nonlinear programming to define the scenarios reflecting ecological safety in the rare earth mining areas. The establishment steps of the model are as follows. In accordance with initial probability matrix $P$ given by experts and mutual influence matrix $K$ between indicators, the following formula can be used to calculate cross-impact probability matrix $P^{\prime}=\left(p_{i j}^{\prime}\right)_{n \times n}$.

$p_{i j}^{\prime}=p_{j}+k_{i j} p_{j}\left(1-p_{j}\right)$
Then, cross-impact probability matrix $P^{\prime}$ is standardized by formula (6) to obtain the transfer matrix $\bar{P}^{\prime}=\left(\bar{p}_{i j}^{\prime}\right)_{n \times n}$.

$$
\vec{p}_{i j}=\frac{p_{i j}^{\prime}}{\sum_{j=1} p_{i j}^{\prime}}
$$

The cross-impact method and Markov chain are combined to calculate the calibrated probability matrix $\hat{P}$ that reflects the development trends of the indicators in the scenario scheme set $E$.

$\hat{P}=\sum P S^{(n)}$

Where, $S^{(n)}$ can be calculated by the following formula. $S^{(n)}=P_{1}^{-1} b$

In above formula, $P_{1}^{-1}$ can be obtained through the transposition of $\overline{P^{\prime}}$ and $b$ can be calculated by the formula (10).

$P_{1}=\left[\begin{array}{ccccc}\vec{p}_{1,1}^{\prime}-1 & \vec{p}_{2.1} & \ldots & \vec{p}_{n-1,1} & \vec{p}_{n, 1}^{\prime} \\ \vec{p}_{1,2}^{\prime} & \vec{p}_{2,2}-1 & \ldots & \vec{p}_{n-1,2} & \vec{p}_{n, 2}^{\prime} \\ \ldots & \ldots & \ldots & \ldots & \ldots \\ \vec{p}_{1, n-1}^{\prime} & \vec{p}_{2, n-1} & \ldots & \vec{p}_{n-1, n-1}^{\prime}-1 & \vec{p}_{n, n-1}^{\prime} \\ 1 & 1 & 1 & 1 & 1\end{array}\right]_{n \times n}$

$b=\left[\begin{array}{c}0 \\ 0 \\ \cdots \\ 0 \\ 1\end{array}\right]_{n \times 1}$

Step-4: Nonlinear programming is used for the fitting of calibrated probabilities in order to minimize the error between the calibrated probability obtained by cross-impact simulation of the initial probability and that obtained through expert opinions. The theoretical probability expressed by scenario probability becomes the minimum. The fitting formula and constraint condition are shown in formulas (11) and (12).

$$
\min \sum_{i=1}(\widetilde{P}(i)-\hat{P}(i))^{2}
$$

$$
\text { s.t. }\left\{\begin{array}{l}
\widetilde{P}(i)=\sum_{k=1} q_{i k} y_{k}, i=1,2, \ldots, n ; k=1,2, \ldots, m \\
\sum_{k=1} y_{k}=1, y_{k} \geq 0 \\
q_{i k}=1, C_{i} \in E_{k} \\
q_{i k}=0, C_{i} \notin E_{k}
\end{array}\right.
$$

Where, $\widetilde{P}(i)$ represents the theoretical probability of $C_{i}$ developing towards the favorable direction. $y_{k}$ is the final scenario probability that reflects the possibility for this 
scenario to appear in the future development. $E_{k}$ is the scenario combination scheme and $q_{i k}$ is the possibility of $C_{i}$ developing towards the favorable direction in $E_{k}$.

\section{Results analysis and discussion}

\subsection{Initial reduction scenario scheme for ecological development trends}

Table. 4. Evaluation opinions of experts

\begin{tabular}{|c|c|c|c|c|c|c|c|}
\hline \multirow{2}{*}{ Indicators } & \multirow{2}{*}{$\begin{array}{l}\text { Initial probability of } \\
\text { indicator }\end{array}$} & \multicolumn{6}{|c|}{ Impact of indicators on other indicators } \\
\hline & & $C_{1}$ & $C_{2}$ & $C_{3}$ & $C_{4}$ & $C_{5}$ & $C_{6}$ \\
\hline$C_{1}$ & 0.7 & 0 & 0.18 & 0.54 & 0.58 & 0.1 & 0.08 \\
\hline$C_{2}$ & 0.39 & 0.1 & 0 & 0.5 & 0.42 & 0.07 & 0.1 \\
\hline$C_{3}$ & 0.54 & 0.1 & 0.08 & 0 & 0.4 & 0.1 & 0.1 \\
\hline$C_{4}$ & 0.58 & 0.13 & 0.07 & 0.31 & 0 & 0.08 & 0.12 \\
\hline$C_{5}$ & 0.72 & 0.71 & -0.1 & 0.68 & 0.76 & 0 & 0.1 \\
\hline$C_{6}$ & 0.77 & 0.81 & -0.14 & 0.64 & 0.72 & 0.58 & 0 \\
\hline
\end{tabular}

Initial probability matrix $P$ and the influence matrix $K$ are obtained based on formula (1) and (2). $P=(0.7,0.39,0.54,0.58,0.72,0.77)$

$$
K=\left[k_{i j}\right]_{6 \times 6}=\left[\begin{array}{cccccc}
0 & 0.18 & 0.54 & 0.58 & 0.1 & 0.08 \\
0.1 & 0 & 0.5 & 0.42 & 0.07 & 0.1 \\
0.1 & 0.08 & 0 & 0.4 & 0.1 & 0.1 \\
0.13 & 0.07 & 0.31 & 0 & 0.08 & 0.12 \\
0.71 & -0.1 & 0.68 & 0.76 & 0 & 0.1 \\
0.81 & -0.14 & 0.64 & 0.72 & 0.58 & 0
\end{array}\right]
$$

As shown in Table 2, ecological safety development in the rare earth mining area mainly involves six factors, and each factor has two states. Therefore, the ecological safety development trends in Lingbei rare earth mining area have 64 scenario combinations at most. Meanwhile, influence matrix $K$ shows that the development of $C_{5}$ and $C_{6}$ toward the favorable direction can exert a strong positive driving effect on the development of other indicators. For example, when $C_{5}$ develops toward the favorable direction, its influence coefficients on $C_{1}, C_{3}$, and $C_{4}$ are $0.71,0.68$, and 0.76 respectively, all of which exceed 0.66 . The experts generally believe that significantly improving the threewaste management technology $\left(C_{5}\right)$ in the rare earth mining area will result in a remarkable improvement of the area's mining technology $\left(C_{1}\right)$, soil environment $\left(C_{3}\right)$, and water environment $\left(C_{4}\right)$. In other words, when the value of $C_{5}$ is 1, the probability for $C_{1}, C_{3}$ and $C_{4}$ to be 0 is lower. Therefore, the scenario combination that $C_{5}$ is 1 and $C_{1}$, $C_{3}$ and $C_{4}$ are 0 can be omitted. The rest can be done in the same manner. After scenario combinations with low probability of occurrence are logically simplified according to the data in matrix $K, 22$ scenario combinations are obtained and used as a basis for further quantitative analysis. They are represented by the scenario scheme set $E=\left(E_{1}, E_{2}, \ldots, E_{22}\right) . E_{k}=\left(e_{c 1}, e_{c 2}, e_{c 3}, e_{c 4}, e_{c 5}, e_{c 6}\right)^{T}$. Scenario scheme set $E$ is shown in Table 5 .
Lingbei ionic rare earth mining area, which is located in Ganzhou City, Jiangxi Province, China, is taken as an example. Officials from governmental environmental protection departments, technical staff in the rare earth mining enterprise and scholars from universities are invited as experts to evaluate the indicators in Table 1 . The results of the evaluation are provided in Table 4.
Table. 5. Scenario scheme set

\begin{tabular}{c|c|c|c|c|c|c}
\hline No & $e_{c 1}$ & $e_{c 2}$ & $e_{c 3}$ & $e_{c 4}$ & $e_{c 5}$ & $e_{c 6}$ \\
\hline$E_{1}$ & 0 & 0 & 0 & 0 & 0 & 0 \\
$E_{2}$ & 0 & 0 & 1 & 0 & 0 & 0 \\
$E_{3}$ & 0 & 1 & 0 & 0 & 0 & 0 \\
$E_{4}$ & 1 & 0 & 0 & 0 & 0 & 0 \\
$E_{5}$ & 0 & 0 & 1 & 1 & 0 & 0 \\
$E_{6}$ & 0 & 1 & 0 & 1 & 0 & 0 \\
$E_{7}$ & 1 & 0 & 0 & 1 & 0 & 0 \\
$E_{8}$ & 0 & 1 & 1 & 0 & 0 & 0 \\
$E_{9}$ & 1 & 0 & 1 & 0 & 0 & 0 \\
$E_{10}$ & 1 & 1 & 0 & 0 & 0 & 0 \\
$E_{11}$ & 1 & 1 & 0 & 1 & 0 & 0 \\
$E_{12}$ & 1 & 1 & 1 & 0 & 0 & 0 \\
$E_{13}$ & 1 & 0 & 1 & 1 & 0 & 0 \\
$E_{14}$ & 1 & 0 & 0 & 1 & 0 & 1 \\
$E_{15}$ & 0 & 1 & 1 & 1 & 0 & 0 \\
$E_{16}$ & 1 & 1 & 1 & 1 & 0 & 0 \\
$E_{17}$ & 1 & 0 & 1 & 1 & 1 & 0 \\
$E_{18}$ & 1 & 0 & 1 & 1 & 0 & 1 \\
$E_{19}$ & 1 & 0 & 1 & 1 & 1 & 1 \\
$E_{20}$ & 1 & 1 & 1 & 1 & 0 & 1 \\
$E_{21}$ & 1 & 1 & 1 & 1 & 1 & 0 \\
$E_{22}$ & 1 & 1 & 1 & 1 & 1 & 1 \\
\hline & & & & & &
\end{tabular}

4.2 Initial reduction scenario scheme for ecological development trends

According to the initial probability matrix $P$ and the mutual influence matrix $K$, the cross-impact probability between indicator $C_{i}$ and $C_{j}$ can be calculated by the formula (5).

Taking the calculation of $p_{12}^{\prime}$ as a example,

$p_{12}^{\prime}=p_{2}+k_{12} p_{2}\left(1-p_{2}\right)$

$=0.39+0.18 \times 0.39 \times(1-0.39)=0.4328$ 
In a similar way, all of $p_{i j}^{\prime}$ can be calculated, the crossimpact probability matrix $P^{\prime}$ for ecological safety in the rare earth mining area can be obtained.

$$
P^{\prime}=\left[p_{i j}^{\prime}\right]_{6 \times 6}=\left[\begin{array}{cccccc}
0.7 & 0.4328 & 0.6741 & 0.7213 & 0.7402 & 0.7842 \\
0.721 & 0.39 & 0.6642 & 0.6823 & 0.7341 & 0.7877 \\
0.721 & 0.409 & 0.54 & 0.6774 & 0.7402 & 0.7877 \\
0.7273 & 0.4067 & 0.617 & 0.58 & 0.7361 & 0.7913 \\
0.8491 & 0.3662 & 0.7089 & 0.7651 & 0.72 & 0.7877 \\
0.8701 & 0.3567 & 0.6990 & 0.7553 & 0.8369 & 0.77
\end{array}\right]
$$

$$
\bar{P}^{\prime}=\left[\begin{array}{llllll}
0.1727 & 0.1068 & 0.1663 & 0.1780 & 0.1826 & 0.1935 \\
0.1812 & 0.0980 & 0.1669 & 0.1715 & 0.1845 & 0.1980 \\
0.1860 & 0.1055 & 0.1393 & 0.1748 & 0.1910 & 0.2033 \\
0.1885 & 0.1054 & 0.1599 & 0.1503 & 0.1908 & 0.2051 \\
0.2023 & 0.0873 & 0.1689 & 0.1823 & 0.1715 & 0.1877 \\
0.2029 & 0.0832 & 0.1630 & 0.1762 & 0.1952 & 0.1796
\end{array}\right]
$$

According to formulas (8)-(10), $S^{(6)}$ is calculated.

The calibrated probability matrix $\hat{P}$ can be calculated according to formula (7).

The cross-impact probability matrix $P^{\prime}$ is standardized according to formula (6), and then matrix $\bar{P}^{\prime}$ can be obtained.

$$
\begin{aligned}
& S^{(6)}=P_{1}^{-1} b=\left[\begin{array}{cccccc}
0.1727-1 & 0.1812 & 0.1860 & 0.1885 & 0.2023 & 0.2029 \\
0.1068 & 0.098-1 & 0.1055 & 0.1054 & 0.0873 & 0.0832 \\
0.1663 & 0.1669 & 0.1393-1 & 0.1599 & 0.1689 & 0.1630 \\
0.1779 & 0.1715 & 0.1748 & 0.1503-1 & 0.1823 & 0.1762 \\
0.1826 & 0.1845 & 0.1910 & 0.1908 & 0.1715-1 & 0.1952 \\
1 & 1 & 1 & 1 & 1 & 1
\end{array}\right]^{-1}\left[\begin{array}{l}
0 \\
0 \\
0 \\
0 \\
0 \\
1
\end{array}\right]=\left[\begin{array}{l}
0.1898 \\
0.0973 \\
0.1608 \\
0.1725 \\
0.1859 \\
0.1937
\end{array}\right] \\
& \hat{P}=\sum_{i=1}^{6} P_{i} S^{(6)}=(0.7+0.39+0.54+0.58+0.72+0.77) \times\left[\begin{array}{l}
0.1898 \\
0.0973 \\
0.1608 \\
0.1725 \\
0.1859 \\
0.1937
\end{array}\right]=\left[\begin{array}{l}
0.7021 \\
0.3600 \\
0.5949 \\
0.6383 \\
0.6880 \\
0.7168
\end{array}\right]
\end{aligned}
$$

According to formulas (11) and (12), the calibrated probability matrix $\hat{P}$ obtained through cross-impact simulation of the initial probability matrix for the ecological safety development trends in Lingbei rare earth mining area is fitted with the theoretical probability matrix $\widetilde{P}$, which reflect development scenarios of indicator in the ecological development process, and then the following fitted equation can be obtained.

$$
\min \left(\left(\widetilde{P}_{1}-0.7021\right)^{2}+\left(\widetilde{P}_{2}-0.36\right)^{2}+\ldots+\left(\widetilde{P}_{6}-0.7168\right)^{2}\right)
$$

$$
\text { s.t. }\left\{\begin{array}{l}
\widetilde{P}_{i}=\sum_{k=1}^{22} q_{i k} y_{k}, i=1,2, \ldots, 6 ; k=1,2, \ldots, 22 \\
\sum_{k=1}^{22} y_{k}=1 \\
q_{i k}=0, C_{i} \notin E_{k} \\
q_{i k}=1, C_{i} \in E_{k}
\end{array}\right.
$$

The above equation is solved via Lingo software. Then, the probability for all kinds of scenario combination schemes of ecological safety development trends is obtained, the result as shown in Table 6 .

Table. 6. Probability of ecological security scenario in Lingbei rare earth mining area

\begin{tabular}{c|c|c|c|c|c|c|c|c|c}
\hline Type & No & $C_{1}$ & $C_{2}$ & $C_{3}$ & $C_{4}$ & $C_{5}$ & $C_{6}$ & $\begin{array}{c}\text { Probability } \\
\text { of scenario } \\
\text { combination }\end{array}$ & $\begin{array}{c}\text { Probability } \\
\text { of scenario } \\
\text { type }\end{array}$ \\
\hline \multirow{2}{*}{1} & $E_{22}$ & 1 & 1 & 1 & 1 & 1 & 1 & $33.6 \%$ & $64.1 \%$ \\
2 & $E_{19}$ & 1 & 0 & 1 & 1 & 1 & 1 & $30.5 \%$ & $27 \%$ \\
3 & $E_{1}$ & 0 & 0 & 0 & 0 & 0 & 0 & $27.4 \%$ & $3.4 \%$ \\
\hline
\end{tabular}

For scenario combinations schemes in Table 5, Accumulative probability of the four scenario combinations in table 6 is $95.1 \%$, and other 18 scenario schemes are all lower than $1 \%$. Thus the 18 scenario schemes can be neglected. It indicate that among the 22 scenario combinations reflecting ecological safety development trends in Lingbei rare earth mining area, the four scenarios in Table 6 have the largest occurrence probability. The above-mentioned four scenario combinations can be divided into three scenario types, where scenario combinations $E_{22}$ and $E_{19}$ belong to type 1, $E_{1}$ belongs to type 2, and $E_{14}$ belongs to type 3 . The occurrence probability of scenario combinations in type 1 is the highest, being $64.1 \%$, followed by that $(27.4 \%)$ in type 2 and that $(3.6 \%)$ in type 3 . The result is shown in Fig. 1. 
Wang Rui, Liu Li-gang, Zhen Ming-gui, Liu Yi-qing, Li Di and Fu hui-juan/

Journal of Engineering Science and Technology Review 12 (5) (2019) 227-234

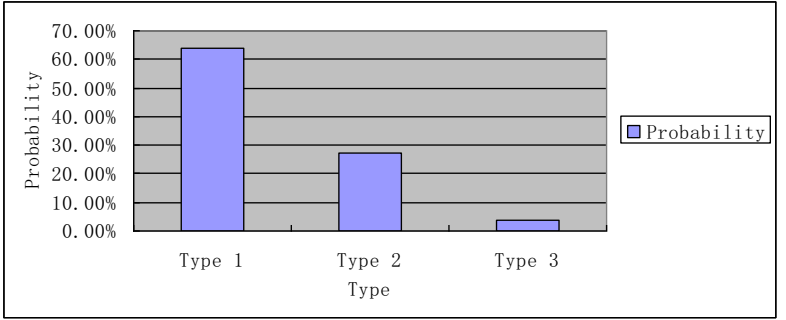

Fig. 1. Occurrence probability graph of all types of scenario combinations

As shown in Fig. 1, the occurrence probability of type 1 is far higher than those of types 2 and 3, and the probability exceeds $60 \%$. It means that most experts deem that scenario combinations in type 1 are scenarios which can most probably reflect ecological safety development trends in the ecological environmental development process of Lingbei rare earth mining area. From Table 6 , it also can be found that the state value of $E_{22}$ and $E_{19}$ on indicator mining technology $\left(C_{1}\right)$, soil environment $\left(C_{3}\right)$, water environment $\left(C_{4}\right)$, three-waste management technology $\left(C_{5}\right)$ and environmental protection policy measures $\left(C_{6}\right)$ are equal to 1. This result manifests that the effect can be more and more remarkable, as the implementation of environmental protection policy measures is enhanced. With the sustainable influence of environmental protection policy, three-waste management technology in the rare earth mining area will be continuously improved. Meanwhile, improvement of environmental protection policy measures and three-waste management technology will facilitate rare earth mining enterprises in the mining area to upgrade mining technology and adopt more environmentally friendly mining technologies like in-situ leaching method. At last, with the improvement of mining technologies and strict control of three-waste discharge, water environment and soil environment in the mining area will be continuously improved and its ecological safety will be in good condition.

According to Fig. 1, the occurrence probability of type 2 is $27.4 \%$, namely: experts commonly believe that this scenario type has a certain probability of occurrence. In this scenario, the state value of mining technology $\left(C_{1}\right)$, mining intensity $\left(C_{2}\right)$, soil environment $\left(C_{3}\right)$, water environment $\left(C_{4}\right)$, three-waste management technology $\left(C_{5}\right)$ and environmental protection policy $\left(C_{6}\right)$ are all 0 , it means that this scenario is bad. The result indicates that improvement of three-waste management technology and standard in the rare earth mining area will be impacted seriously, when the implementation of environmental protection policy measures is loosened just a bit. Moreover, the improvement of mining technology of rare earth mining enterprises will be bound to suffer from a serious negative impact. Consequently, the soil environment and water environment in mining area becomes poor. In the end, the ecological safety will be stuck in a vicious cycle.

type 3 is a kind of ecological safety development scenario in the rare earth mining area, which is between scenario types 1 and 2 . The experts believe that the occurrence probability of this scenario is low. From Fig.1, it can be found that its occurrence probability is only $3.6 \%$. According to Table 6 , the values of $C_{6}, C_{4}$ and $C_{1}$ are all 1 in this scenario, while other values are all 0 . It indicates that this scenario is an intermediate state. If the implementation of environmental protection policy measures in the mining area is continuously enhanced, this scenario will be transited into the scenario in type 1. The literature [21] and [25] indicates that the implementation and sustainability of environmental protection policy play a significant role in the ecological safety development in the mining area. If environmental protection policy measures are strengthened continuously, rare earth mining enterprises will continuously improve mining technology and three-waste management technology in order to prevent rectification and shutdown punishments due to disqualification after environmental assessment. For instance, they will adopt more environmentally friendly ionic exchange liquids in the rare earth mining process, and as a result, state value of $C_{1}$ will be kept at 1 . As the state value of $C_{1}$ is kept at 1 , it will surely improve "three-waste" management levels of enterprises so that state value of $C_{5}$ in the mining area will become 1 . With the elevation of three-waste management level, "water environment" and "soil environment" in the mining area are improved in the end, namely: state values of $C_{3}$ and $C_{4}$ are finally turned into 1 , thus realizing transition from scenario type 3 into type 1 . If the implementation of environmental protection policy is slackened just slightly, violation cost of mining enterprises will be reduced by a large margin, so they will slow down and even stop upgrading work of mining technologies, and even some enterprises may reuse backward mining technologies in order to lower their costs, which will turn state value of $C_{1}$ into 0 . As the mining technology is deteriorated, three-waste management will also be aggravated in the mining area so that the state value of $C_{5}$ is 0 . With the deterioration of three-waste management, it will certainly cause a severe negative impact on water environment and soil environment, and consequently, their state values will both be turned into 0 so as to lead to transition of scenario type 3 into scenario type 2. Therefore, the key to whether scenario type 3 is transited into scenario 1 or scenario 2 lies in whether environmental protection policy measures in the mining area can be strictly implemented, namely: scenario type 3 can be transited into scenario type 1 only when the state value of $C_{6}$ is always equal to 1 , or otherwise scenario type 3 is transited into scenario type 2 .

\section{Conclusion}

During the development process of rare earth resources, the state values of evaluation indicators for ecological safety in the mining area are dynamic. In order to perform an accurate quantitative analysis of ecological development trends in the rare earth mining area, cross-impact probability, Markov chain and nonlinear programming method have been integrated to construct a quantitative scenario analysis model. The proposed model was verified through ecological safety data in Lingbei rare earth mining area located in Ganzhou City, China. The conclusions were drawn as follows.

One is the quantitative scenario analysis model can realize a quantitative analysis of state value changes of six indicators-"mining technology", "mining intensity", "water environment", "soil environment", "three-waste management technology" and "environmental protection policy measures", as well as their cross-impacts.

The other is the quantitative scenario analysis model can calculate probabilities of occurrence of scenario combinations of ecological safety development in the mining 
area, which are formed by state changes of these six indicators, so as to determine its ecological safety development trends.

This study has adopted a quantitative scenario analysis model to conduct a quantitative analysis of ecological development trends in the rare earth mining area, which is of great significance to ecological environment planning and repair in the rare earth mining area. However, the proposed method is also limited to calculating the scenario probabilities dependence partly on the subjective data. The objective data like water environment data should be utilized to calculate the scenario probabilities in the future studies.

\section{Acknowledgements}

This work was supported by social science foundation of China (Grant No. 15BJY060), social science foundation of Ganzhou (Grant No. 18061), Mining developments research center project of Jiangxi University of science and technology (Grant No. KYZX2017-3), and key research base project of Jiangxi (Grant No. JD18087)

This is an Open Access article distributed under the terms of the Creative Commons Attribution License

\section{References}

1. Fan, X. S., Gao, J. X., He P., Feng, C. Y., Xu, J., Hou, L. P., Ren, Y., Wang, D. W., Jia, J., Hou, C. F., "Technical solutions for ecological red-line management based on problems of ecological security". China Environmental Science, 38(12), 2018, pp.47494754.

2. Li, H. K., Yang, L., Wang, X. L., “Assessment of ecological security in Rare earth mining area based on PSR model". Journal of Applied Science and Engineering, 21(1), 2018, pp.9-16.

3. Liang, X. D., Ye, M., Yang, L., Fu, W., Li, Z., "Evaluation and Policy Research on the Sustainable Development of China's Rare Earth Resources". Sustainability, 10(10), 2018, pp.3792.

4. Gosselin, M., Bonhême, I., Archaux, F., Nivet, C., "National follow-up of forest biodiversity-overview, areas for improvement". Revue Forestière Française , 64(5), 2012, pp.665-682.

5. Sun, J., Li, Y. P., Gao, P. P., Xia, B. C., "A Mamdani fuzzy inference approach for assessing ecological security in the Pearl River Delta urban agglomeration, China”. Ecological Indicators, 94(11), 2018, pp.386-396.

6. Cen, X. T., Wu, C. F., Xing, X. S., Fang, M., Garang, Z. M., Wu, Y. Z., "Coupling Intensive Land Use and Landscape Ecological Security for Urban Sustainability: An Integrated Socioeconomic Data and Spatial Metrics Analysis in Hangzhou City". Sustainability, 7(2), 2015, pp. 1459-1482.

7. Rapport, D. J., Hildén, M., "An evolving role for ecological indicators: from documenting ecological conditions to monitoring drivers and policy responses". Ecological Indicators, 28, 2013, pp.10-15.

8. Seydehmet, J., Lv, G. H., Abliz, A., Shi, Q. D., Abliz, A., Turup, A., "Irrigation salinity risk assessment and mapping in arid oasis, Northwest China". Water, 10(7), 2018, pp.966-990.

9. Shi, Y. X., Li, J. Q., Xie, M. Q., "Evaluation of the ecological sensitivity and security of tidal flats in Shanghai". Ecological Indicators, 85(2), 2018, pp.729-741.

10. Neri, A. C., Dupin, P., Sánchez, L. E., "A pressure-state-response approach to cumulative impact assessment". Journal of Cleaner Production, 126, 2016, pp.288-298.

11. Malenović Nikolić, J., Vasović, D., Filipović, I., Mušicki, S., Ristović, I., "Application of Project Management process on environmental management system improvement in miningenergy complexes". Energies, 9(12), 2016, pp.1071-1090.

12. He, G., Yu, B. H., Li, S. Z., Zhu, Y. N., "Comprehensive evaluation of ecological security in mining area based on PSRANP-GRAY”. Environmental Technology, 39(23), 2018, pp.3013-3019.

13. Ke, X. L., Feng, M., Xiang, M., "Fuzzy comprehensive evaluation in the evaluation of ecological security in coal mine areas". International Journal of Networking and Virtual Organisations, 18(1), 2018, pp.80-96.
14. Stecyk, A., "The AHP-TOPSIS Model in the Analysis of the Counties Sustainable Development in the West Pomeranian Province in 2010 and 2017'. Journal of Ecological Engineering, 20(7), 2019, pp. 233-244.

15. Alilou, H., Rahmati, O., Singh, V. P., Choubin, B., Pradhan, B., Keesstra, S., Ghiasi, S. S., Sadeghi, S. H., "Evaluation of watershed health using Fuzzy-ANP approach considering geoenvironmental and topo-hydrological criteria". Journal of Environmental Management, 232, 2019, pp.22-36.

16. Xue, X. L., Wang, X. M., Hu, Y., Yang L., "Ecological security effect evaluation of mine based on fuzzy analytical hierarchy process and variable fuzzy sets". Journal of Northeastern University, 37(1), 2016, pp.94-99.

17. Wang, Z. H., Yang, L., Yin, J. H., Zhang, B., “Assessment and prediction of environmental sustainability in China based on a modified ecological footprint model". Resources, Conservation and Recycling, 132, 2018, pp.301-313.

18. Quiceno, G., Álvarez, C., Ávila, R., Óscar, F., Carlos, J. F., Martin, K., Isaac, D., "Scenario analysis for strategy design: A case study of the Colombian electricity industry". Energy Strategy Reviews, 23, 2019, pp. 57-68.

19. Höltl, A., Macharis, C., De, Brucker. K., "Pathways to decarbonise the European car fleet: A scenario analysis using the backcasting approach". Energies, 11(1), 2018, pp.20-39.

20. Walz, R., "Development of Environmental Indicator Systems: Experiences from Germany". Environmental Management, 25(6), 2000, pp.613-623.

21. Kapustka, K., Klimecka-Tatar, D., Ziegmann, G., "The Management and Potential Risk Reductionin the Processing of Rare Earths Elements". System Safety: Human-Technical Facility-Environment, 1(1), 2019, pp. 77-84.

22. He, X. Y., Zheng, C. L., Sui, X., Jiang, Q. G., Wu, X., Wang, J. Y., Si, W. T., Zhang, X. F., "Biological damage to SpragueDawley rats by excessive anions contaminated groundwater from rare earth metals tailings pond seepage". Journal of Cleaner Production, 185, 2018, pp. 523-532.

23. Romero-Freire, A., Minguez, L., Pelletier, M., Cayer, A., Caillet, C., Devin, S., Gross, E. M., Guérold, F., Pain-Devin, S., Vignati, D. A. L., Giamberini, L., "Assessment of baseline ecotoxicity of sediments from a prospective mining area enriched in light rare earth elements". Science of the Total Environment, 612, 2018, pp.831-839.

24. Lai, C. S., Tao, Y. S., Xu, F. Y., Wing, W.Y. Ng., Jia, Y. W., Yuan, H. L., Huang, C., Lai, L. L., Xu, Z., Giorgio, L., “A robust correlation analysis framework for imbalanced and dichotomous data with uncertainty". Information Sciences, 470, 2019, pp.5877.

25. Wang, S. R., Meng, W., Jin, X. C., Zheng, B. H., Zhang, L., Xi, H. Y., "Ecological security problems of the major key lakes in China”. Environmental Earth Sciences, 74(5), 2015, pp.38253837. 